\title{
FR177391, A New Anti-hyperlipidemic Agent from Serratia
}

\author{
IV. Target Identification and Validation by Chemical Genetic Approaches \\ Makiko Yamaoka, Kentaro Sato ${ }^{\dagger}$, Motoo Kobayashi ${ }^{\dagger}$, Nobuya Nishio ${ }^{\dagger}$, \\ Mitsuru Ohkubo ${ }^{\dagger}$, Takashi Fujii ${ }^{\dagger}$, Hidenori Nakajima ${ }^{\dagger}$
}

Received: March 29, 2005 / Accepted: October 6, 2005

(C) Japan Antibiotics Research Association

\begin{abstract}
Natural products with distinct biological activities are very promising molecular probes to dissect the novel pathways of biology. FR177391, a product of bacteria, was obtained as a natural compound possessing anti-hyperlipidemic effects. FR177391 enhances differentiation of mouse 3T3-L1 fibroblasts to adipocytes and reduces the circulating levels of triglyceride in $\mathrm{C} 57 \mathrm{BL} / \mathrm{KsJ}-\mathrm{db} / \mathrm{db}$ mice, a obese non-insulin-dependent diabetes mellitus animal model, although its mechanism of actions remained to be unknown. We report here that the target protein for FR177391 was identified to be protein phosphatase 2A (PP2A) by employing the method of affinity chromatography. FR177391 potently inhibited PP2A activity at nano molar concentration, and shared its binding pocket with a phosphatase inhibitor, okadaic acid. In addition to the phenotypic alterations, the enhancement for phosphorylation of extracellular signal-regulated kinase (ERK) protein was observed in the FR177391-treated 3T3L1 cells. These results suggest that prolonged activation of ERK protein due to inhibition of its dephosphorylation by PP2A plays an important role in adipocyte maturation and regulation of the blood revels of lipids.
\end{abstract}

Keywords PP2A, inhibitor, chemical genetics, FR177391

\section{Introduction}

To dissect a novel biological event, one determines the cellular function of known proteins that may be implicated in it by altering their activities. The most common way is an indirect genetic approach (e.g., deletion, knock-out or overexpression) in the genes encoding proteins of interest. A complementary and direct approach is the use of small molecule compounds, especially natural products, possessing unique biological activities of interest. Small molecule natural products actually have been opening new windows of biology so far [1 17]. Although the approach using small molecules have some advantages of genetic ones (e.g., it allows genes to be turned off after completion of an organism's development), in many cases their target proteins are unknown. Progresses in the technology of the affinity chromatography [18] and bioconversion accompanied with chemical synthesis enable one to identify the target proteins of rare or complex natural compounds that used to be difficult to be modified.

Hyperlipidemia is a major problem of the obese noninsulin-dependent diabetes mellitus (NIDDM). Known drug target proteins in the lipid control are HMG-Co A reductase in liver [19] and peroxisome proliferatoractivated receptors (PPARs) in adipocytes [20]. Many drugs targeting these proteins are used in the clinic and being developed. In the course of the screening for new anti-hyperlipidemia drugs, we have found a product of Serratia liquefaciens, FR177391 (Fig. 1) [21 23]. FR177391 potently enhanced the differentiation of mouse 3T3-L1 fibroblasts to mature adipocytes with oil droplets. The oral administration of FR177391 to C57BL/KsJ-db/db
H. Nakajima (Corresponding author), M. Yamaoka, K. Sato, M. Kobayashi, N. Nishio, M. Ohkubo, T. Fujii: Exploratory Research Laboratories, Fujisawa Pharmaceutical Co., Ltd., 2-3, 5-chome, Tokodai, Tsukuba, Ibaraki 300-2698, Japan.
E-mail: hidenori.nakajima@jp.astellas.com

† Present address: Astellas Pharma. Inc., 5-2-3 Tokodai, Tsukuba, Ibaraki 300-2698, Japan 


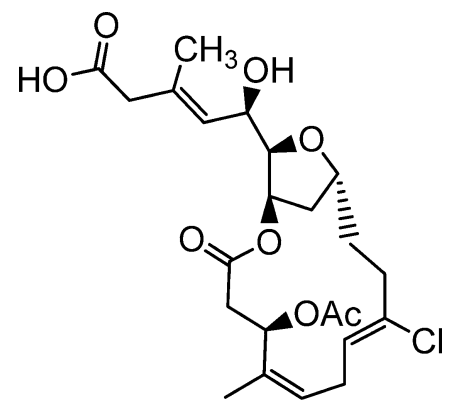

Fig. 1 Chemical structure of FR177391.

NIDDM model mice also reduced the blood levels of triglyceride. Thus, target proteins of FR177391 were supposed to be implicated in the unknown control machinery of lipid metabolism.

In this report, we identified protein phosphatase $2 \mathrm{~A}$ (PP2A) as the target protein of FR177391 by an affinity chromatography. FR177391 actually inhibited the phosphatase activity of purified PP2A protein. Its specificity for phosphatase inhibition is $\mathrm{PP} 2 \mathrm{~A} \gg \mathrm{PP} 1>\mathrm{PP} 2 \mathrm{~B}$. Interestingly, FR177391 competes with okadaic acid (OA), phosphatase inhibitor [24], on the binding to PP2A. In addition to morphological changes, we detected the enhancement of ERK protein phosphorylation in the FR177391-treated 3T3-L1 cells. OA also induced the same effect. Together, these results indicate the one possibility that the control of PP2A activity in the mitogen-activated protein (MAP) kinase pathway plays important roles in lipid metabolism of adipocytes and the whole body.

\section{Materials and Methods}

\section{Cells and Reagents}

3T3-L1 cells were purchased from American Type Culture Collection. FR177391 was prepared in Fujisawa Pharmaceutical Co. Ltd. OA was purchased from Upstate Biotechnology Inc. Rosiglitazone was prepared in Fujisawa Pharmaceutical Co. Purified human PP2A, bovine PP2B, rabbit PP1 and recombinant human PTP-1B were purchased from Upstate Biotechnology Inc.

\section{Adipogenesis Assay}

3T3-L1 fibroblasts were grown into confluence in the complete growth medium (Dulbecco's modified Eagle's medium (DMEM, Sigma) supplemented with 10\% Fetal Bovine Serum (FBS) and penicillin/streptomycin (PS)). At two days after confluence, the medium was changed to the induction medium (DMEM supplemented with 10\% FBS,
PS, $5 \mu \mathrm{g} / \mathrm{ml}$ insulin, $0.5 \mathrm{mM}$ 3-isobutyl-1-methylxanthine and $1 \mu \mathrm{M}$ dexamethazone). After 48 hours incubation, the medium was changed to the maintenance medium (DMEM supplemented with $10 \%$ FBS, PS and $5 \mu \mathrm{g} / \mathrm{ml}$ insulin) with or without compounds tested. The number of fully differentiated round shape adipocytes was counted under microscopic observation to determine the activity of compounds at three days after the treatment.

\section{ERK Phosphorylation Assay}

3T3-L1 cells differentiating with induction medium for 48 hours were treated with compounds for the indicated times. After the treatment, the cells were lysed in cell lysis buffer (Cell Signaling Technology, \#9803) containing $1 \mathrm{mM}$ PMSF. Samples were subjected to SDS-polyacrylamide gel electrophoresis (SDS-PAGE) and transferred to nylon membranes. Phosphorylated ERK and MAPK/ERK kinase (MEK) were detected by immunoblot with antibodies against phosphorylated ERK and MEK (Upstate Biotechnology Inc.). In the case of cell-free phosphorylation assay, the cell lysates were employed instead of living cells and incubated with compounds at $37^{\circ} \mathrm{C}$ for 5 minutes.

\section{Synthesis of the Bait and Lure}

Bio-conversion of FR177391 to 20-hydroxy and 3-hydroxy FR177391 and chemical synthesis of biotin-labeled FR177391 are reported in the previous paper.

\section{Affinity Chromatography}

$1 \times 10^{8}$ cells of differentiating 3T3-L1 were suspended with $1 \mathrm{ml}$ of buffer A ( $50 \mathrm{mM}$ Tris-HCl pH 8.5, $250 \mathrm{mM}$ Sucrose) and lyzed by sonication. The lysate was centrifuged at $100,000 \times g$ for 45 minutes at $4^{\circ} \mathrm{C}$ to be removed cell debris. The supernatant were treated with or without $10 \mu \mathrm{M}$ of competitors for 1 hour and then incubated with $1 \mu \mathrm{M}$ of biotin-labeled FR177391 for 2 hours. The resultant lysate was passed through PD-10 desalting columns (Amersham pharmacia biotech) equilibrated with buffer A containing $0.15 \mathrm{M}$ of $\mathrm{NaCl}$ (buffer B) to be removed the free biotin-labeled FR177391. The flow-though fraction of PD-10 column was subjected to the avidin-conjugated sepharose column $(50 \mu \mathrm{l}$ of gel bed volume, PIERCE Chemical Inc.) equilibrated with buffer B containing $0.3 \%$ of CHAPS (buffer C) after addition of CHAPS. The resin was washed thoroughly with buffer $\mathrm{C}$ and then retained proteins were eluted by $10 \mu \mathrm{M}$ FR177391 and $8 \mathrm{M}$ urea solution sequentially. Each elute was resolved by SDS-PAGE electorophoresis with $4 \sim 12 \%$ Bis-Tris/glycine gradient gels (Invitrogen). Proteins separated on gel were visualized by silver-staining. 


\section{Identification of PP2A}

The protein bands were cut out from the gel and In-gel digestion was carried out according to the modified Shevchenko's method [25]. All procedures prior to trypsinization were kept as keratin-free as possible. All chemicals were analytical grade from the manufactures. For identification of the proteins binding to FR177391, the mass spectrometric analysis was carried on an electrospray ionization tandem mass spectrometer, ESI-QTOF hybrid instrument. After collecting data, the database searches were carried out with the program MASCOT.

\section{Phosphatase Assay}

The Effect of compounds on PP2A and PP1 phosphatase activity was measured in triplicate in 96-well flat-bottomed microtiter plates. Free phosphate released by the phosphatases from their substrate peptides was visualized by using the malachite green system (Upstate Biotechnology Inc.) according to the manufacturer's instruction. p-nitrophenylphosphate (pNPP, Sigma Inc.) was used as the substrate for PP2B and PTP-1B. The enzyme activity was monitored by kinetic analysis of the absorbance at $405 \mathrm{~nm}$.

\section{Results and Discussion}

\section{Adipogenesis-enhancing Effect of FR177391}

Although adipogenesis plays major roles in lipid homeostasis and diseases such as insulin resistance and hyperlipidemia, it remains to be determined what signaling pathways are involved [26 34]. 3T3-L1 fibroblasts are widely used as an in vitro model of adipogenesis [35 39]. The cells can be converted to adipocytes by culturing in the induction medium supplemented with insulin, 3-isobutyl-1methylxanthine and dexamethazone. Adipocytes induced have characteristic morphological features such as round cells with many oil droplets (Fig. 2). To characterize the effects of anti-hyperlipidemia agent FR177391 on adipogenesis, we compared the activities of known agents on 3T3-L1 fibroblasts with that of FR177391. Treatment of FR177391 greatly enhanced the adipocyte induction (Fig. 2D). On the other hands, TNF- $\alpha$, one of the cytokines that cause abnormal lipid metabolisms in NIDDM patients [40], completely blocked the adipogenesis of 3T3-L1 cells (Fig. 2B). Interestingly, FR177391 also abolished this blockade (Fig. 2C). Rosiglitazone, a PPAR- $\gamma$ agonist, which improves insulin-resistance and hyperlipidemia [41, 42], magnified adipogenesis as well as FR177391 albeit its efficacy is weaker than FR177391 (Fig. 2E). These results indicate that an enhancing signal triggered by
FR177391 is much stronger than either signal of PPAR- $\gamma$ induced activation and TNF- $\alpha$ induced suppression. Hyper modulation or deregulation of an activity of proteins located in a signaling pathway was suspected to occur in FR177391-treated 3T3-L1 cells.

\section{Enhancement of ERK Phosphorylation by FR177391}

As TNF- $\alpha$ suppresses conversion of 3T3-L1 fibroblasts to adipocytes, its signaling pathway is supposed to participate in adipogenesis [35, 43]. In addition, FR177391 can overcome the effect. It is possible that TNF- $\alpha$ and FR177391 use a common pathway. To investigate this possibility, we checked the activation status of kinases located in MAP kinase pathway [38]. Treatment of 3T3-L1 cells with TNF- $\alpha$ transiently induced phosphorylation of MEK and ERK, followed by their rapid dephosphorylation (Lane 1 of Figs. 3A and B). This shows TNF- $\alpha$ triggered signal transduction pathway based on phosphorylation and dephosphorylation of MAP kinase cascade. On the other hand, FR177391 rapidly induced hyperphosphorylation of ERK, following to its delayed dephosphorylation (Lane 2 and 3 of Fig. 3B). As the phosphorylation of MEK was not so prominent compared with ERK (Lane 2 of Fig. 3A), ERK hyperphosphorylation is supposed not to be due to phosphorylation of ERK by deregulated activation of MEK. The reason why TNF- $\alpha$ and FR177391 induce the contradictory biological outputs albeit their same ERK phosphorylation effects remains to be unknown. One possible explanation is that the aberrant phosphorylation status of ERK proteins breaks the inhibitory signal which is induced by the transient phosphorylation of ERK proteins with TNF- $\alpha$.

\section{A Bait and Lure for the Affinity Chromatography}

To verify the protein implicated in the induction of hyperhosphorylation of ERK leading to enhancement of adipogenesis, we tried to purify the binding proteins of FR177391 by biotin/avidin affinity chromatography. To do this, we prepared two types of the affinity probe, the bait and the lure. The bait, biotin-labeled FR177391, was synthesized from 20-hydroxy FR177391 obtained by bioconversion using fungi, conjugating with $\mathrm{N}-(+)$ biotinyl-6-aminocaproic acid (Fig. 4A). The lure, 3hydroxy FR177391, was also prepared by bioconversion of FR177391 (Fig. 4A). Biological activities of these probes are also shown in Fig. 4A. The bait retained the enhancingactivity of adipogenesis using 3T3-L1 cells although it was a hundred times less active than FR177391. However, in the cell-free ERK phosphorylation assay, the bait had a comparable activity with FR177391 (Fig. 4B). Biotinlabeling may affect on its cell-permeability of FR177391. 

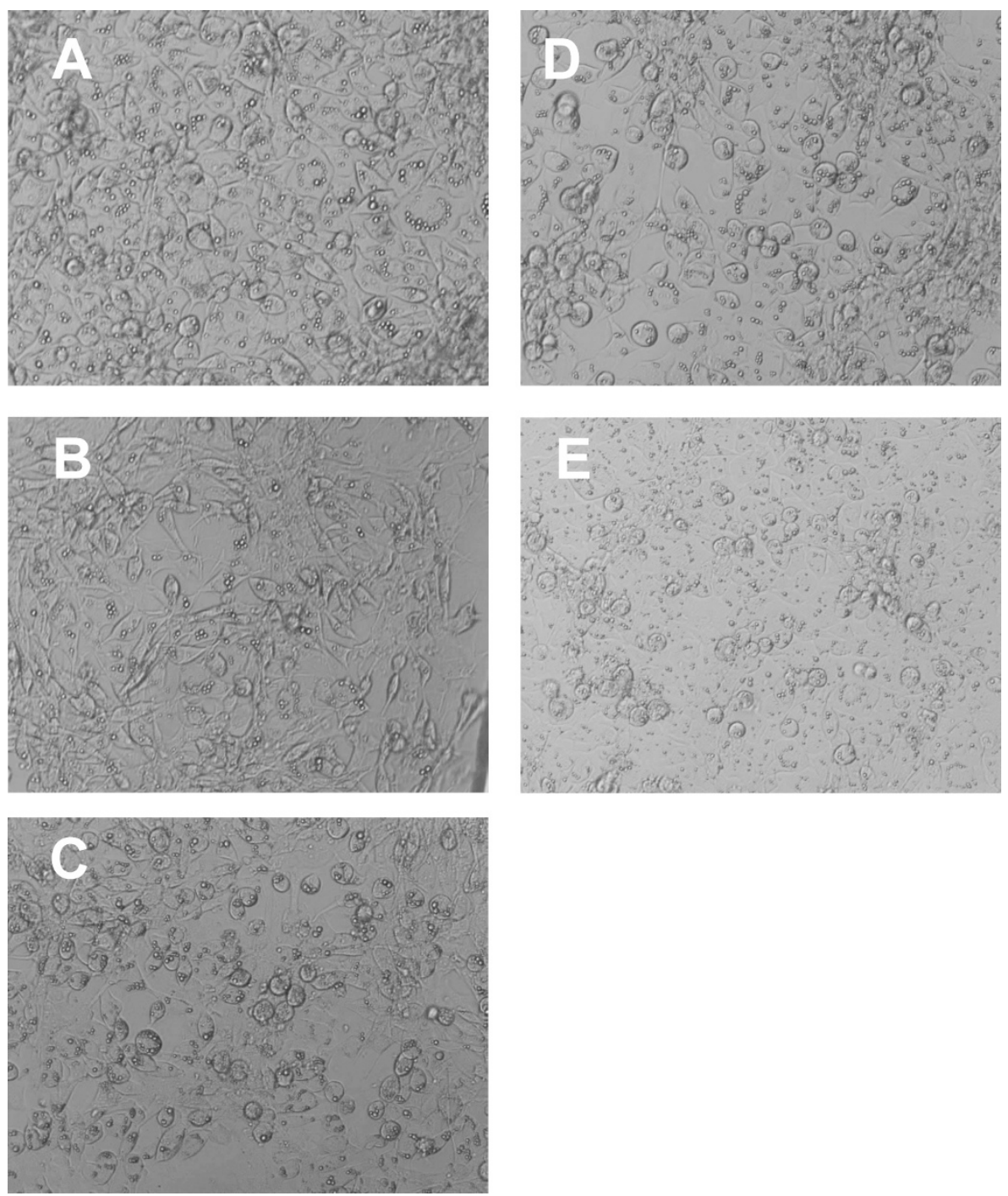

Fig. 2 Enhancement of adipogenesis by FR177391.

3T3-L1 fibroblast was induced differentiation to adipocytes by induction medium after confluency. Two days after induction, the medium was changed to the maintenance medium with (B; TNF- $\alpha$, C; TNF- $\alpha+F R 177391$, D; FR177391 and E; rosiglitazone) or without (A) compounds. Fully differentiated round shape adipocytes was observed under microscope $(\times 100$ magnitude field $)$ at three days after the treatment.

The lure had no activity in either assay system (Fig. 4B).

Thus, we succeeded to prepare two affinity probes; one is the bait that will be used to pick up the targets of FR177391, another is the lure that is closely related to FR177391 but impotent to be used in the validation of the proteins trapped by the bait.

\section{Affinity Purification of the Target Protein for FR177391} Biotin/avidin choromatography was employed to purify the target proteins. The bait was added to a cell extract prepared from 3T3-L1 fibroblast induced to adipocytes and incubated with or without competitors (FR177391 or the lure). Proteins captured by the bait were trapped by avidin- conjugated agarose resins and sequentially eluted with FR177391 and $8 \mathrm{M}$ urea solutions. Eluted proteins were subjected to polyacrylamide gel electrophoresis (PAGE). The silver-stained gel of the FR177391 elutes revealed two major polypeptides with apparent molecular weights, $60 \mathrm{kD}$ and $35 \mathrm{kD}$ (Fig. 5A, lane 2). The binding of the bait to $\mathrm{p} 60$ and p35 appeared to be specific, because these polypeptides are not retained when the incubation was done with FR177391 nor avidin resin alone without the bait (Fig. 5A, lane 1 and 3 ). The specificity of binding is further confirmed by the fact that the retention of two polypeptides to avidin resins was not disturbed by the lure (Fig. 5A, lane 4). The urea elutes contained substantial amount of $\mathrm{p} 35$, 
A

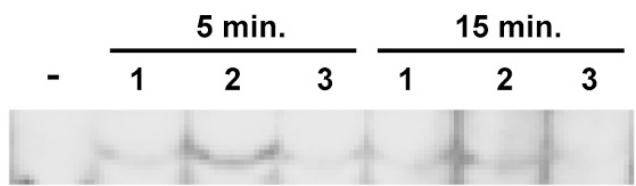

p-MEK1/2

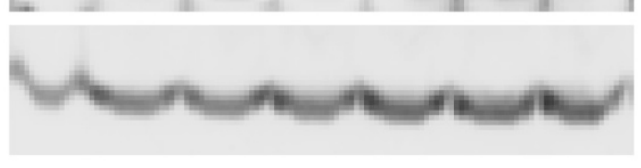

MEK1/2

B

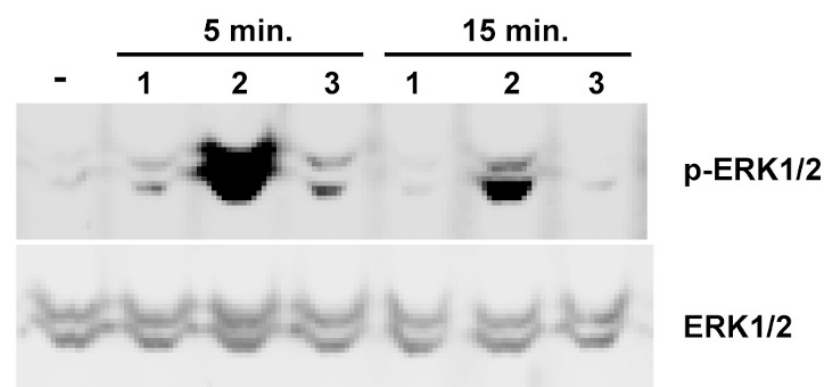

Fig. 3 Enhancement of ERK1/2 phosphorylation on FR177391-treated 3T3-L1 adipocyte.

3T3-L1 cells under differentiation to adipocytes were treated with TNF- $\alpha$ (lane 1), $10 \mu \mathrm{M}$ of FR177391 (lane 2) or $1 \mu \mathrm{M}$ of FR177391 (lane 3) for the indicated times. The treated cells were lysed, subjected to SDS-PAGE and then immunoblotted with antibodies against phosphorylated MEK (A) and ERK (B). The amount of proteins in each lane was also determined by reprobing with antibodies against ERK and MEK (lower panels of $A$ and $B)$.

A

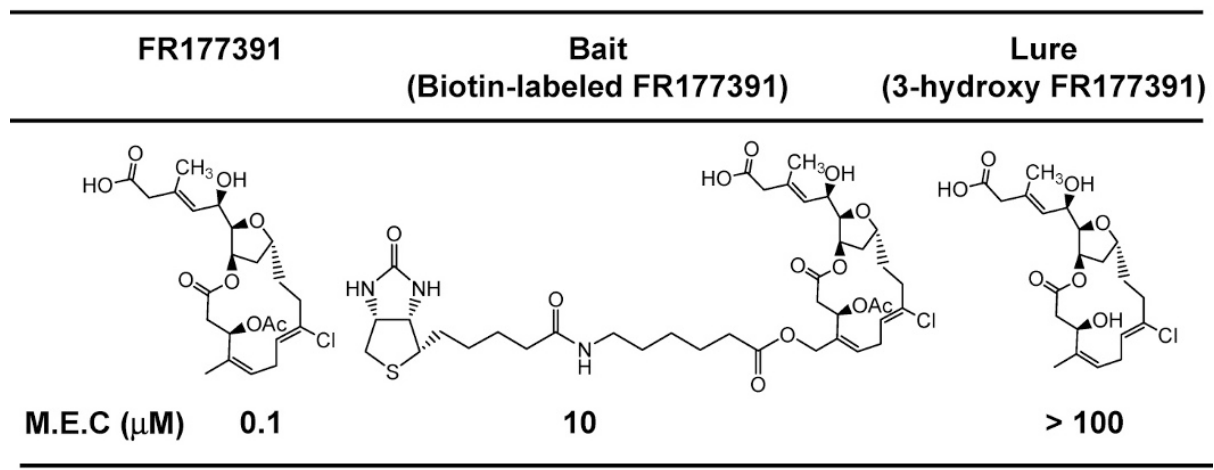

B

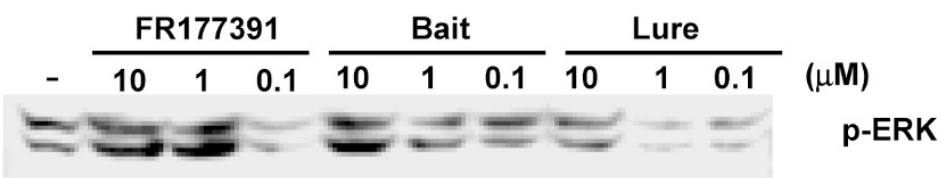

Fig. 4 Bait and Lure.

Chemical structures of the bait and the lure and their biological activities are shown in (A). Biological activities were determined by adipogenesis-enhancing effect on 3T3-L1 fibroblasts as described in Materials and Methods. MEC shows minimum enhancing concentration. Biological activities of the bait and the lure was determined by the cell-free phosphorylation assay (B). The cell lysates were incubated with 0.1 to $10 \mu \mathrm{M}$ of compounds at $37^{\circ} \mathrm{C}$ for 5 minutes. The resultant lysates were determined the enhancing effect of ERK phosphorylation as in Fig. 3. 
A

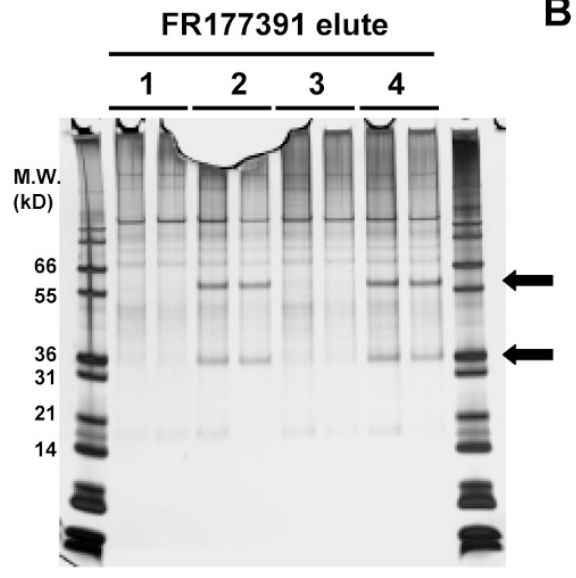

B

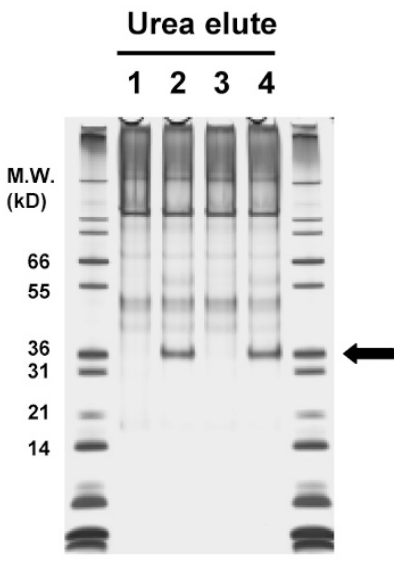

C

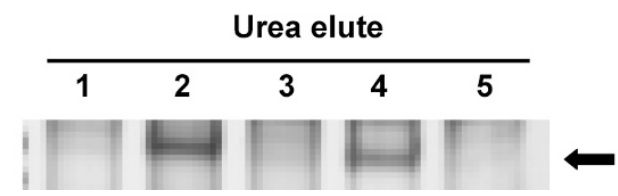

Fig. 5 Identification of the proteins specifically binding to FR177391.

Biotin/avidin affinity chromatography using the bait and lure was performed as described in the Materials and Methods. SDS-PAGE resolutions of proteins eluted from the avidin-sepharose resin by $10 \mu \mathrm{M}$ of FR177391 solution (A) and following $8 \mathrm{M}$ of urea solution (B and C) are shown. Binding of the bait to proteins in the lysate was done in the presence (FR177391; lane 3, the lure; lane 4) or absence (lane 2) of competitors. Non specific binding of proteins to avidin resin was also investigated without the bait (lane 1). The protein bands pointed by upper and lower arrows indicate PP2A regulatory subunit and PP2A catalytic subunit, respectively. In (C), in addition to FR177391 (lane 3) and the lure (lane 4), okadaic acid was added to the lysate as a competitor (lane 5). Only the resolution of urea elute was shown.

showing that the binding affinity of the bait to p35 is stronger than $\mathrm{p} 60$ or that $\mathrm{p} 60$ is an associated polypeptide with $\mathrm{p} 35$ primary binding to the bait (Fig. 5B).

The stained protein bands were cut out from the polyacrylamide gel and digested by trypsin within the gels. Resultant peptide fragments were extracted from the gels and submitted for the mass spectrometry to analyze the exact mass of peptides. Peptide mass fingerprints were queried to database to identify the protein. The $60 \mathrm{kD}$ and $35 \mathrm{kD}$ proteins corresponded to mouse protein phosphatase 2A (PP2A), regulatory subunit, and PP2A, catalytic subunit, respectively. Considering the results of affinity chromatograpy, we suppose that the primary target of FR177391 is PP2A catalytic subunit associated with regulatory one.

\section{Biological Relevance of PP2A as the Target Protein for FR177391}

PP2A comprises a family of serine/threonine phosphatases and plays a prominent role in the regulation of specific signal transduction cascades to produce various important biological events such as cell cycle transition, cell morphological change and development [44]. To validate
Tabel 1 Inhibitory effect of FR177391 and OA on phosphatases

\begin{tabular}{ccc}
\hline & \multicolumn{2}{c}{$K i(\mathrm{nM})$} \\
\cline { 2 - 3 } Phosphatase & FR177391 & OA \\
\cline { 2 - 3 } PP2A & 2.90 & 2.55 \\
PP1 & 7,853 & 133 \\
PP2B & N.E. & N.E. \\
PTP-1B & N.E & N.D. \\
\hline
\end{tabular}

N.E.: No effect (i.e., no significant inhibition was not observed in the concentration of $100 \mu \mathrm{M}$ )

N.D.: Not determined

the binding of FR177391 to PP2A, we investigated whether FR177391 inhibits the phosphatase activity of PP2A. As shown in Table 1, FR177391 potently inhibited PP2A activity with $2.90 \mathrm{nM}$ of $K i$ value. OA, a well-known inhibitor for protein phosphatases, also inhibited PP2A with a comparable activity to FR177391 (Table 1). Rosiglitazone did not inhibit PP2A at all (data not shown). 


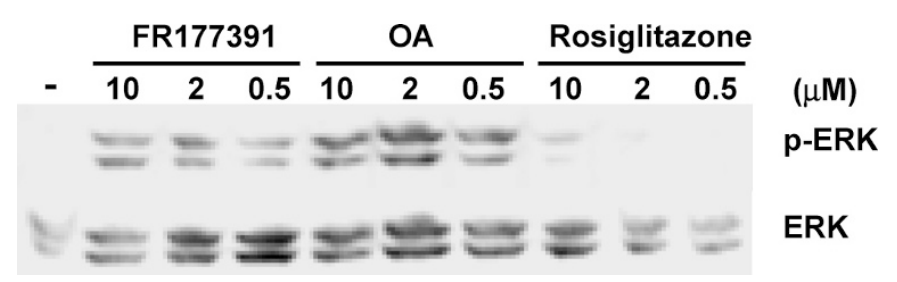

Fig. 6 Induction of hyperphosphorylation of ERK by OA.

The cell lysates were incubated with 0.5 to $10 \mu \mathrm{M}$ of compounds and then determined the enhancing effect of ERK phosphorylation as in Fig. 3.

The similar mode of action of FR177391 to OA was further demonstrated by the binding competition experiment to PP2A. PP2A can be purified by the bait from induced 3T3L1 cells whereas the presence of FR177391 abolished it, showing that the bait share its binding pocket to PP2A with FR177391 (Fig. 5A and B, lane 3). OA also completely disturbed the binding of the bait to PP2A as FR177391 did (Fig. 5C, lane 5). These results suggest that FR177391 inhibits PP2A phospahatase activity in the same mode of action with $\mathrm{OA}$.

To investigate the phosphatase specificity of FR177391 inhibition, PP1, PP2A and PP2B were prepared to measure the inhibitory activity of FR177391. As shown in Table 1, FR177391 showed much more preferential inhibition for PP2A than OA. Again. the lure which is biologically inactive was also impotent on the PP2A inhibition (data not shown).

To explain the biological relevance of PP2A inhibition by FR177391, we examined the effect of OA on ERK phosphorylation accompanied with FR177391. Although OA has a poor cell-permeability, it is reported to induce the activation of MAP kinases in treated cells [45, 46]. We used the cell-free ERK phosphorylation assay to investigate the effect of OA more precisely. As shown in Fig. 6, OA induced hyperphosphorylation of ERK as FR177391 did. Rosiglitazone failed to show the effect as well. Unfortunately, the effect of OA on adipogenesis failed to be determined due to its potent cytotoxic effect.

Together, these results demonstrate that FR177391 specifically binds to PP2A and inhibit its phosphatase activity, leading to hyperphosphorylation of ERK in the adipocytes induced adipogenesis by its treatment. Due to the limitation of chemical genetic approach, we have obtained no direct biological evidence to convince the relationship between anti-hyperlipidemic activity and PP2A inhibition. Although further biological study but not chemical genetic one will be needed, the missing link between MAP kinase cascade under the control of PP2A and the lipid metabolism as well as adipogenesis was suggested by a cell-permeable and highly selective inhibitor reinforced with chemical genetic approach.

Acknowledgements We are deeply grateful to Hiromi Sasamura for her critical experiments.

\section{References}

1. Harding MW, Galat A, Uehling DE, Schreiber SL. A receptor for the immunosuppressant FK506 is a cis-trans peptidyl-plolyl isomerase. Nature 341: 758-760 (1989)

2. Bierer B, Mattila PS, Standaert RF, Herzenberg LA, Burakoff SJ, Crabtree GC, Schreiber SL. Two distinct signal transmission pathways in $\mathrm{T}$ lymphocytes are inhibited by complexes formed between an immunophilin and either FK506 or rapamycin. Proc Natl Acad Sci USA 87: 92319235 (1990)

3. Bierer BE, Somers PK, Wandless TJ, Burakoff SJ, Schreiber SL. Probing immunosuppressant action with a nonnatural immunophilin ligand. Science 250: 556-559 (1990)

4. Schreiber SL. Chemistry and biology of the immunophilins and their immunosuppressive ligands. Science 251: 283-287 (1991)

5. Hultsch T, Albers MW, Schreiber SL, Hohman RJ. Immunophilin ligands demonstrate common features of signal transduction leading to exocytosis or transcription. Proc Natl Acad Sci USA 88: 6229-6223 (1991)

6. Liu J, Farmaer JD Jr, Lane WS, Friedman J, Weissman I, Schreiber SL. Calcineurin is a common target of cyclophilin-cyclosporin A and FKBP-FK506 complexes. Cell 66: 807-815(1991)

7. Brown EJ, Albers MW, Shin TB, Ichikawa K, Keith CT, Lane WS, Schreiber SL. A mammalian protein targeted by G1-arresting rapamycin-receptor complex. Nature 369: 756-758 (1994)

8. Brown EJ, Beal PA, Keith CT, Chen J, Shin TB, Schreiber SL. Control of p70 S6 kinase by kinase activity of FRAP in vivo. Nature 377: 441-446 (1995)

9. Fenteany G., Standaert RF, Lane WS, Choi S, Corey EJ, Schreiber SL. Inhibition of proteasome activities and subunit-specific amino-terminal threonine modification by lactacystin. Science 268: 726-731 (1995)

10. Taunton J, Hassig CA, Schreiber SL. A mammalian histone 
deacetylase related to the yeast transcriptional regulator Rpd3p. Science 272: 408-411 (1996)

11. Kwon HJ, Owa T, Hassig CA, Shimada J, Schreiber SL. Depudecin induces morphological reversion of transformed fibroblasts via the inhibition of histone deacetylase. Proc Natl Acad Sci USA 95: 3356-3361 (1998)

12. Griffith EC, Su Z, Turk BE, Chen S, Chang YH, Wu Z, Biemann KB, Liu JO. Methionine aminopeptidase (type 2) is the common target for angiogenesis inhibitors AGM-1470 and ovalicin. Chem Biol 4: 461-471 (1997)

13. Sin N, Meng L, Wang MQW, Wen JJ, Bornmann WG, Crews C. Proc Natl Acad Sci USA 94: 6099-6103 (1997)

14. Kudo N, Matsumori N, Taoka H, Fujiwara D, Schreiner EP, Wolff B, Yoshida M, Horinouchi S. Leptomycin B inactivates CRM1/exportin 1 by covalent modification at a cysteine residue in the central conserved region. Proc Natl Acad Sci USA 96: 9112-9117 (1999)

15. Nakajima H, Kim YB, Terano H, Yoshida M, Horinouchi S. FR901228, a potent antitumor antibiotic, is a novel histone deacetylase inhibitor. Exp Cell Res 25: 126-133 (1998)

16. Nakajima H, Hori Y, Terano H, Okuhara M, Manda T, Matsumoto S, Shimomura K. New antitumor substances, FR901463, FR901464 and FR901465. II. Activities against experimental tumors in mice and mechanism of action. J Antibiot 49: 1204-1211 (1996)

17. Ki SW, Kasahara K, Kwon HJ, Eishima J, Takesako K, Cooper JA, Yoshida M, Horinouchi S. Identification of radicicol as an inhibitor of in vivo Ras/Raf interaction with the yeast two-hybrid screening system. J Antibiot 51: 936-944 (1998)

18. Shimizu N, Sugimoto K, Tang J, Nishi T, Sato I, Hiramoto M, Aizawa S, Hatakeyama M, Ohba R, Hatori H, Yoshikawa T, Suzuki F, Oomori A, Tanaka H, Kawaguchi H, Watanabe $H$, Handa H. High-performance affinity beads for identifying drug receptors. Nat Biotechnol 18: 877-881 (2000)

19. Endo A. Compactin (ML-236B) and related compounds as potential cholesterol-lowering agents that inhibit HMG-CoA reductase. J Med Chem 28: 401-405 (1985)

20. Tontonoz $\mathrm{P}, \mathrm{Hu} \mathrm{E}$, Spiegelman BM. Stimulation of adipogenesis in fibloblasts by PPAR $\gamma 2$ a lipid-acivated transcription factor. Cell 79: 1147-1156 (1994)

21. Sato B, Nakajima H, Fujita T, Takase S, Yoshimura S, Kinoshita T, Terano H. FR177391, a new anti-hyperlipidemic agent from Serratia. I. Taxonomy, fermentation, isolation, physico-chemical properties, structure elucidation and biological activities. J Antibiot 58: 634-639 (2005)

22. Inami M, Kawamura I, Tsujimoto S, Yasuno T, Lacey E, Hirosumi J, Takakura S, Nishigaki F, Naoe Y, Manda T, Mutoh S. FR177391, a new anti-hyperlipidemic agent from Serratia. II. Pharmacological activity of FR177391. J Antibiot 58: 640-647 (2005)

23. Kobayashi M, Sato K, Yoshimura S, Yamaoka M, Takase S, Ohkubo M, Fujii T, Nakajima H. FR177391, a new antihyperlipidemic agent from Serratia. III. Microbial conversion of FR177391 and synthesis of FR177391 derivatives for its target protein screening by chemical genetic approaches. J Antibiot 58: 648-653 (2005)

24. Dounay AB, Forsyth CJ. Okadaic acid: the archetypal serine/threonine protein phosphatase inhibitor. Curr Med Chem 9: 1939-1980 (2002)

25. Shevchenko A, Wilm M, Vorm O, Mann M. Mass spectrometric sequencing of proteins from silver-stained Polyacrylamide Gels. Anal Chem 68: 850-858 (1996)

26. Gurnell M, Savage DB, Chatterjee VK, O'Rahilly S. The metabolic syndrome: peroxisome proliferator-activated receptor gamma and its therapeutic modulation. J Clin Endocrinol Metab 88: 2412-2421 (2003)

27. Kersten S. Peroxisome proliferator activated receptors obesity. Eur J Pharmacol 440: 223-234 (2002)

28. Diamant M, Heine RJ. Thiazolidinediones in type 2 diabetes mellitus: current clinical evidence. Drugs 63: 1373-1405 (2003)

29. Holst D, Grimaldi PA. New factors in the regulation of adipose differentiation and metabolism. Curr Opin Lipidol 13: 241-245 (2002)

30. Mukherjee R, Hoener PA, Jow L, Bilakovics J, Klausing K, Mais DE, Faulkner A, Croston GE, Paterniti JR Jr. A selective peroxisome proliferator-activated receptor-gamma (PPARgamma) modulator blocks adipocyte differentiation but stimulates glucose uptake in 3T3-L1 adipocytes. Mol Endocrinol 14: 1425-1433 (2000)

31. Wu Z, Puigserver P, Spiegelman BM. Transcriptional activation of adipogenesis. Curr Opin Cell Biol 11: 689-694 (1999)

32. Sorisky A. From preadipocyte to adipocyte: differentiationdirected signals of insulin from the cell surface to the nucleus. Crit Rev Clin Lab Sci 36: 1-34 (1999)

33. Spiegelman BM. PPAR-gamma: adipogenic regulator and thiazolidinedione receptor. Diabetes 47: 507-514 (1998)

34. Wang S. 9th International Conference on Obesity, NIDDM, adipogenesis and insulin resistance. Expert Opin Investig Drugs 9: 1673-1678 (2000)

35. Souza SC, Palmer HJ, Kang YH, Yamamoto MT, Muliro KV, Eric Paulson K, Greenberg AS. TNF-alpha induction of lipolysis is mediated through activation of the extracellular signal related kinase pathway in 3T3-L1 adipocytes. J Cell Biochem 89: 1077-1086 (2003)

36. Song H, O'Connor KC, Papadopoulos KD, Jansen DA. Differentiation kinetics of in vitro 3T3-L1 preadipocyte Cultures. Tissue Eng 8: 1071-1081 (2002)

37. Watanabe M, Inukai K, Katagiri H, Awata T, Oka Y, Katayama S. Regulation of PPAR gamma transcriptional activity in 3T3-L1 adipocytes. Biochem Biophys Res Commun 10: 429-436 (2003)

38. Prusty D, Park BH, Davis KE, Farmer SR. Activation of MEK/ERK signaling promotes adipogenesis by enhancing peroxisome proliferator-activated receptor gamma (PPARgamma ) and C/EBPalpha gene expression during the differentiation of 3T3-L1 preadipocytes. J Biol Chem 277: 
46226-46232 (2002)

39. Stephens JM, Butts M, Stone R, Pekala PH, Bernlohr DA. Regulation of transcription factor mRNA accumulation during 3T3-L1 preadipocyte differentiation by antagonists of adipogenesis. Cell Biochem 123: 63-71 (1993)

40. Hotamisligil GS, Spiegelman BM. Tumor necrosis factor alpha: a key component of the obesity-diabetes link. Diabetes 43: 1271-1278 (1994)

41. Greene DA. Rosiglitazone: a new therapy for Type 2 diabetes. Expert Opin Investig Drugs 8: 1709-1719 (1999)

42. Werner AL, Travaglini MT. A review of rosiglitazone in type 2 diabetes mellitus. Pharmacotherapy 21: 1082-1099 (2001)

43. Stephens JM, Pekala PH. Transcriptional repression of the GLUT4 and C/EBP genes in 3T3-L1 adipocytes by tumor necrosis factor- $\alpha$. J Biol Chemi 266: 21839-21845 (1991)

44. Janssens V, Goris J. Protein phosphatase 2A: a highly regulated family of serine/threonine phosphatases implicated in cell growth and signaling. Biochem J 353: 417-439 (2001)

45. Amaral MC, Casillas AM, Nel AE. Contrasting effects of two tumour promoters, phorbol myristate acetate and okadaic acid, on T-cell responses and activation of p42 MAP-kinase/ERK-2. Immunology 79: 24-31 (1993)

46. Casillas AM, Amaral K, Chegini-Farahani S, Nel AE. Okadaic acid activates p42 mitogen-activated protein kinase (MAP kinase; ERK-2) in B-lymphocytes but inhibits rather than augments cellular proliferation: contrast with phorbol 12-myristate 13-acetate. Biochem J 290: 545-50 (1993) 